\title{
Refereed Articles
}

\section{Making Hope and History Rhyme}

\section{Reflections on Popular Education and Leadership Following a Visit to Highlander}

\author{
Bríd Connolly, EdD ${ }^{1}$ and Fergal Finnegan, $\mathrm{PhD}^{1}$
} \begin{abstract}
explicitly political and collective than individual psychological concepts of learning. The Highlander experience provided the opportunity to interrogate related assumptions that underpin the concept of leadership, pointing toward a more collective and political framework. The article uses feminist critical theories as lenses for this interrogation,
\end{abstract}

Abstract: This article draws on our backgrounds as adult educators in Ireland and our experience at Highlander in 2014. We review our development as critical educators, exposed to deep inequalities in Irish society. We explore role of popular education in fostering social change, beginning with the commitment to equality and freedom, whereby, we produce emancipatory knowledge with students and participants. This learning process is more holding that equality and freedom are mutually constitutive principles of critical practice. Popular educators foster critical thinking and reflection. The Other's Tools, drawing on the precept that traditional thinking reinforces the status quo. These critical thinking tools are vital to question the assumptions that power and control in society as individualized or de-politicized. We take this learning into our practice in Ireland.
Keywords: popular education, social movements, critical practice, feminisms, leadership theories

History says, don't hope

On this side of the grave.

But then, once in a lifetime

The longed-for tidal wave

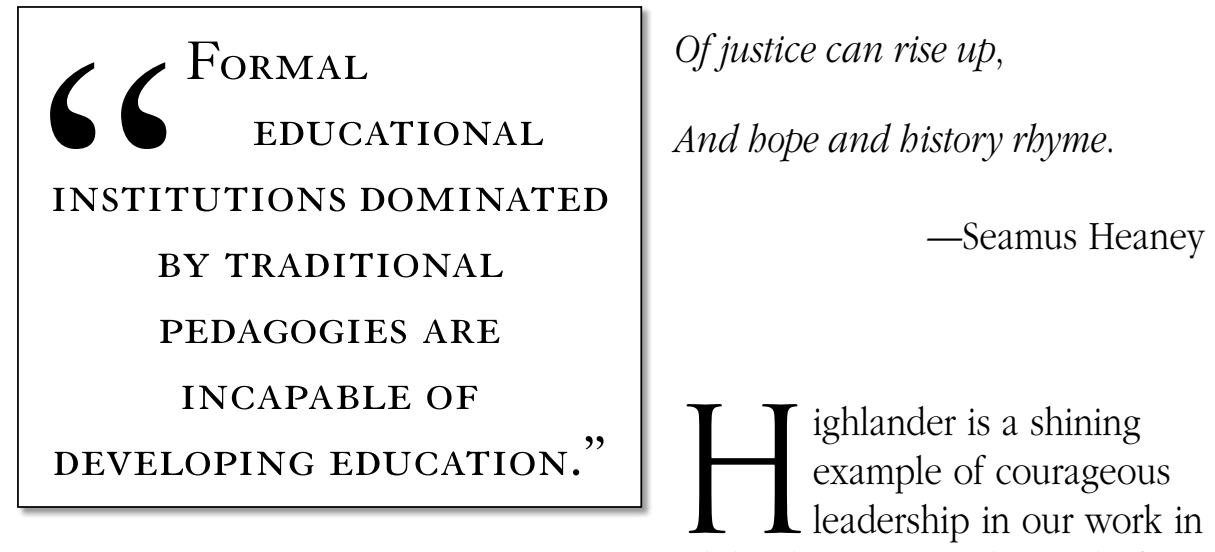
adult education. We learned of Highlander through our studies and our colleagues in the Popular Education Network (PEN). Highlander has fed into the creation of emancipatory learning environments and influenced the work of social movement activists in Ireland. However, neither of us had visited Highlander, and we were overjoyed with the opportunity to travel to Ball State University as visiting scholars. This included a trip to Highlander 
with our new colleagues to participate in the learning program on authentic leadership in the iconic roundroom full of rocking chairs.

Highlander's vision of a better world and the acknowledgment of the profound struggle to attain it provide a beacon of hope in inequality's darkness (Adams \& Horton, 1975; Horton, 2003; Horton \& Freire, 1990). In this article, we reflect on this participation, explore our reaction to the place and what it represents, and contemplate our experiences with the intensive course and how we brought this learning home. To contextualize these reflections and our visions for the future, we begin by describing how we became popular educators and delineating our conception of popular education.

\section{Yes, It's Personal and Political!}

We believe that it is impossible to separate the personal and political. We act, think, and speak out our lived, embodied, and storied experience. Our pedagogical choices and our approach to writing a piece such as this also emerge from biographies made within collective histories. To clear the ground for dialogue with you, the reader, we introduce ourselves as people who came to Highlander with particular experiences, expectations, ideas, and commitments.

Just a note, when we use $I$ and $w e$, we refer to ourselves rather than the wider community of popular educators or social activists; however, we align ourselves with these groups.

\section{Bríd Connolly}

During my studies in philosophy, I was influenced by the work of Beauvoir (1949/2010) and the wider philosophy underpinning equality and justice. When I started in adult education, this influence stayed with me, particularly in the aftermath of the anti-abortion amendment of 1983. In 1989, I worked with a project for unemployed people and applied this personal/ political perspective to wider groups including men, people with disabilities, and other minorities. I had a philosophy and a practice, but almost no theory until I read Freire (1972) and Horton and Freire (1990). These texts introduced me to popular education and supplemented the feminist literature with the critical acuity of Freire and Horton. There are deep inequalities around class, gender, and ethnicity in Ireland due to the complex interplay of power and control in the new, post-colonial, theocratic state. The women's movement was one of the most significant and responsive social movements that characterized the 20th century (Connolly, 2002). It is also significant in terms of other social movements, particularly in the interrogation of disability, ethnicity, race, and most recently, sexuality, as witnessed by the 2015 popular vote for marriage equality.

Furthermore, feminist pedagogy has deepened the interrelationships between learners and educators, particularly in terms of care, power, and knowledge. In Ireland, popular education draws on learning, which emerged in women's community education, while connecting with the wider contexts especially through the PEN including adult and higher educators committed to equality and social justice.

\section{Fergal Finnegan}

I began as a volunteer in a community education project in Dublin's inner city. I certainly had no clear philosophy of education at that stage. At first, I was primarily interested in finding a way of making the classroom "work." This was an intuitive and vaguely comprehended aim, and progress was slow and haphazard. I grasped that I had to learn how these students saw things and bring their interests into the room. It also became clear that traditional curricula would not work and that each group and context required background research. My experiences made me think about why I thought certain texts or ideas were valuable in the first place, and why the vibrancy, resilience, and humor are so often leeched out of people when they are confronted by what is deemed "the best that is thought and said" (Arnold, 1960, p. iii). This meant confronting how my class background and university experience had shaped my prior assumptions about education. I began to use different criteria for judging the worth of an educational encounter.

Enthusiasm, passion, relevance to students' lived experience, discussion which leads to questioning, and students taking ownership over the form and content of classes seemed more useful to me than achieving specific prescribed outcomes or demonstrating knowledge of a particular poem or film.

My interactions with students, Irish working class people, and recently arrived migrants made me view 
education from their perspective. I began to understand their lives and life worlds, and I became aware of my blind spots and ignorance. For example, I knew so little about other non-European cultures. It forced me to consider how power works and how savage inequalities in power and wealth affect people's lives. In other words, my students educated me in the true sense of that word-they posed problems and brought forth something new in me.

Critical concepts were needed to bring these intuitions, lessons, and impressions together in a coherent manner and to think through education in a more systematic way (Sayer, 1992). This is why Freire (1972) was such a revelation. I had read him prior to becoming an educator and thought the dense, poetic ideas about education were interesting, but they seemed quite removed from me in space and time. Yet, reading him again when faced by the very real issues of power negotiation, curriculum design, and my own niggles about adequacy as an educator, and trying to make sense of complex student experiences was quite another matter. Freire also allowed me to think about how what occurs in a classroom might relate to my commitment to social justice and my experience in social movements. Freire helped me clarify thoughts and experience, sharpen conceptual distinctions, and make hidden connections visible.

\section{How Do We Understand Popular Education?}

For feminists and Freireans, popular education begins with a commitment to equality and freedom and a desire to produce emancipatory knowledge with students. Basically, this means building respectful, open, and equal relationships, and critically exploring lived experience together. It also means seeking and facilitating an open and flexible pedagogical process through which dialogue and critical analysis create new understandings of the world. This involves ensuring that processes are participatory and discovering concepts, so that learners can effectively reframe and act upon their own world. We seek to develop a pedagogy that taps into people's sense of their own power, agency, and imagination and to encourage high levels of self-management. This process of learning is more collective and explicitly political than the idea of self-direction popularized by andragogy. To carry this philosophical approach forward, we, together with our colleagues, established a master's degree within our adult and community education program based on popular education principles in which we "learn from each other struggles."

In this sense, we hold very ambitious aims. We want to reflect upon and consciously work toward economic and social equality to provide people with the conditions and resources necessary to live dignified and flourishing lives. This type of education requires a dual focus: "identifying the ways in which existing social institutions and social structures impose harms on people" (Wright, 2010, p. 11) and simultaneously asking how social relations could be altered to allow for "the expansion of the 'capabilities' of persons to lead the lives they value-and have reason to value" (Sen, 1999, p. 18). This means, as feminists have long argued, fully acknowledging the centrality of love, solidarity, and care for social well-being, as well as seeking to identify and foster the social and institutional arrangements that support and enhance these things (Kittay, 1999; Lynch, Baker, Lyons, \& Cantillon, 2009).

It is integral to any popular education initiative that time is given to puzzling out what we mean by emancipation and in exploring how ideas of emancipation can be realized. It is helpful in this sense to think of equality and freedom as mutually constitutive principles in popular education. The multidimensional concept of equality, which includes equality in terms of cultural and economic resources and access to valued social practices, also entails a commitment to political equality based on a "thick" notion of participatory democracy. Substantive equality and freedom involves working toward "citizens having equal, effective possibility of participating in legislating, governing, and judging, and in the last analysis, in instituting society" (Castoriadis, 2010, p. 3). Pursuing equality and democracy calls for enormous changes in how we produce knowledge and organize education (Horton, 2003; Wainwright, 2009). Popular education anticipates this sort of future and makes it more likely to emerge.

\section{The Significance of Highlander}

These ideas, values, and commitments meant that traveling to a world famous center of popular education, Highlander Research and Education Center, 
was very important to us. It has long been an inspiring example of what can be done through education: a place of fire, of passionate commitment to freedom and equality, from which hope can be ignited and spread.

Highlander's trade union activity, its programs linked to mining and the environment, and its projects promoting global solidarity are remarkable. The better known history of the center's role in the civil rights movements and the literacy and civil disobedience campaigns are just as inspirational. Alluding to particular campaigns and initiatives, to historical high points and famous figures, may miss the most important point about Highlander though. For more than 80 years, Highlander has shown an extraordinary capacity to listen to local people and link this to national and international events and movements. This has meant Highlander has developed and changed focus as events unfolded in response to needs, rather than being owned by any specific campaign or dominated by one particular political current or ideology. It has offered space for generations of activists and several waves of social movements to develop strategies and hone practices linked to the struggle for freedom, democracy, and human dignity (Adams \& Horton, 1975; Horton, 2003). The longevity of Highlander means that it is a place alive with history. It is a history of complex, storied, vibrant struggles of nameless thousands who passed through, debated, organized, and acted in their own interests, who have fed the global radical imagination. People have also risked a great deal in the struggle for equality and social justice and have faced violence, intimidation, and prosecution for their efforts.

\section{Leadership}

Popular education in and beyond Highlander involves rethinking power, knowledge, and participation in a very profound way. This is why we often have a sense of unease when the topic of leadership arises. Leadership-that smooth and assured term-is frequently used in a way that bypasses an examination of power. It can smuggle in ideas and practices that are not emancipatory. This is why attending the course on leadership at a popular education center initially not only created a sense of dissonance but also offered a valuable opportunity to put the term under sustained scrutiny. In spite of the best intentions, the wider social assumptions can seep into the most sacred and revered learning spaces. In Highlander, this was particularly noticeable. We felt as if the hierarchical relationships in hegemonic models of leadership usurped Freirean praxis and critical consciousness. In effect, this meant that there was a focus on personal, individual failure or success. The questions became, "Who is to blame? Who is to be commended (and rewarded)?" The problem-posing experience would have been better by asking, "What are the causes of achievements or problems? Why? And how can we collectively respond?"

This dissonance created the space for dialogue. On one hand, the tension was perceived as gender based, that is, the domination of hegemonic masculinities. This was a powerful, influential perception. On the other hand, it was seen as the use and abuse of power and authority within business models of leadership. Thus, the dialogical space enabled the group collectively to tease out the issues as each of us experienced them. We were also able to facilitate ourselves to address these issues with the complexities, ambiguities, and uncertainties that characterize human relationships, with all the privilege and oppressions that emanate from social inequality.

The remainder of the article offers a summary of our thoughts on leadership and popular education, which emerged from attending the course.

Bríd Connolly argues that leadership in popular education is like negative space artwork, where the complementary space around the concept defines the representation, being more important than the concept itself. For Fergal Finnegan, it is best approached as a collective capacity rather than an individual quality (Freire, 1972; Shor, 1987).

When we hear leadership being discussed, our first question always has to be, "Who then are the followers? Our second question is, "Are we being asked in a given discussion of leadership to focus on collective processes or individual qualities?"

In answer to these two questions, we argue that for popular educators, there are no followers; rather, there are people with the potential to participate in an active and responsive way, not as passive, inert, or submissive subjects, which is usually implied in the term followers. For us, the typical conceptions of leadership offered in most educational institutions, at workplaces, in much of the literature on leadership, and in popular culture are 
deeply problematic. How they are premised on an active minority, often a single charismatic individual, leading the passive and meek majority is an obstacle to learning and social equality.

The very idea of leadership has to be problematized in classrooms and social movements from the outset, and popular educators have to actively subvert traditional individualistic and hierarchical notions of "good" leadership. The first and last discovery in a popular education space has to be that we have the freedom and ability to reinvent how power is shared.

As discussed earlier, adult educators and practitioners foster the practice of critical thinking, reflection, and action. Freire's (1972) praxis fuses the intellectual and the practical, as comparable and complementary processes, rather than unequal, inferior/superior binary opposites. Furthermore, the role of social dialogue shifts us from the purely psychological domain in thinking and reflection into the social and cultural domain. Dialogue is the precondition of praxis and develops the transformation of experience into the transformation of the world.

This complex practice entails making the connections between our learning and experience, and mapping how social practices, relations, ideologies, and discourses can shape our complex inner world. Issues around class, gender, ethnicity, and myriad other social categories forge connections with the internal and external worlds of others, including their personalities and other social dimensions. All of these factors are mediated in the environment through powerful social factors, structures, and forces. This social component is missing from psychological theories that focus on the individual as a "natural" unit of analysis and decontextualizes and dehistorices human activity (Harré, 1993; Vygotsky, 1978).

For popular educators, critical thinking should equip us with the set of skills, proficiencies, approaches, and political awareness to ensure that we are able to think and act for ourselves. Learners do not want to be at the mercy of passivity, on one hand, or temporary, provisional, social, and cultural trends on the other. Brookfield (1995) fosters the imperative to practice critical reflection as adult educators when he claimed that "We teach to change the world" (p. 1).

We are critically reflective when we examine our own assumptions and challenge their origins. We also critically interrogate the values that underpin the purpose and meaning of educational work and its role in this reproduction. Simultaneously, we foster an environment for critical thinking and reflection for our students. hooks (1994) proposes that resisting the norms and boundaries of classrooms, communities, and societies will change the world. As popular educators, we are intent on transformation, as we create the environment, whereby our students develop alternative ideas about the way things are. The world we want to change is the world that alienates and excludes us on many grounds, from gender, race, ethnicity, ability/ disability, and sexuality. The world we want to create is one where there is room for all of us. This world would be a truly democratic, egalitarian, just society making the connections between personal and social agency, and the institutional and structural social, political, and economic world.

When we get together in learning environments and communities, we bring these elements into the mix: critical thinking, reflection, agency, analysis, dialogue, in addition to other personal qualities and social values. These values underpin equality such as: fairness, ethical practice, social justice, equity, feminism, human rights; alongside those perceptions of inequality: meritocracy, hierarchy, patriarchy in many forms, and models and structures. This eclectic mix constitutes the complementary space for the so-called non-leaders, which necessarily raises the question, "Who are the leaders?" In discerning who they are, those in leadership roles themselves often propose a kind of Be Like Me cloning. They define leadership with reference solely to their own qualities and traits.

As was pointed out during the Authentic Leadership Workshop, about 600 books are published each year on leadership, particularly leadership in industrial and organizational studies, perpetuating this cloning process. This falls into the problem raised by David Hume (2009) more than 200 years ago that the description of any quality becomes the prescription of that quality, however flawed the reasoning, assumptions, or belief is behind it. This is known as the is-ought fallacy.

\section{Leadership: The Is-Ought Fallacy}

When we examine the actual personalities and traits of people in leadership roles and compare them with 
qualities that define individual leaders, the is-ought fallacy materializes. If the leaders identify their own qualities as leadership qualities, then, the fallacy goes, those are the qualities that leaders should have. The theories around leadership in organizations and industry are especially prone to this fallacy, thereby continuously reproducing leaders with certain qualities and outcomes that promote the status quo. The persistence of the trait approach to leadership demonstrates that the focus is underpinned by the belief that certain traits will result in effective outcomes of that leadership. Therefore, people are selected, valorized, and promoted as leaders if they possess these traits. Although many of these traits are balanced and ethical and may not cause harm, some leaders or leadership theories do not have a moral compass. This is clear when we look at the global leadership crises, with the scramble for power and authority through whatever means possible, both democratic and non-democratic. Anyone who protests the scramble for power is viewed as different compared with the leadership. They are Othered, to use Beauvoir's (1949/2010) apt concept, while those in power are seen as the One. It is almost irresistibly seductive to view groups and communities who do not share our own culture and values as the Other. Yet, this is where a feminist lens is so useful to be inclusive and to share leadership across a variety of groups.

\section{Othering and Leadership}

Social analysis shows that many groups are subjected to degradation and vilification through mythology, misrepresentation, and criticism. In Ireland, those governing the country, both the colonists and the aristocracy attributed negative traits to those who did not succumb to their rule. For example, historically and in some current contexts, the native Irish were depicted as lazy, stupid, indolent, rebellious, slothful, and sly. These traits are currently applied to people living in poverty, people of color, minority ethnic groups, and so on, not just in Ireland but also across the world. This default setting of Othering subordinate groups and populations has clear implications on what kind of leadership emerges. The perceptions of The One and Others perpetuate inequality and inequity and exclude a huge portion of the population from the opportunity to gain a foothold in decision making and influence. There are critical lenses to help us analyze these exclusions, and the feminist lens is also a particularly useful one (hooks, 2000).

\section{The Others'Tools}

The master's tools will never dismantle the master's house, as Lorde (1994) contends. We propose the creation of the Others' (Beauvoir, 1949/2010) tools. These tools help us to reflect on the limitations of the traditional, masculine, elitist ways of thinking about leadership. First, the Others' tools challenge the persistence of the essentialist views of gender, with the perception that women's essential traits include submission, passivity, lacking rationality and logic, at the mercy of the emotions and instinct, and are therefore unable to lead.

Second, feminists have revisited patriarchy and its ubiquity even when women hold power. Patriarchy prevails as the dominant hierarchy in most social and cultural institutions and, therefore, continues to subordinate women. Drawing on Beauvoir's (1949/2010) statement that "one is not born, but rather, becomes a woman" (p. 267), reframes not just the way to think about women in society but also about society itself. Thus, we become in that ontological sense by the way of self-creation and engagement.

When we look at traditional leadership, with the absence of women, except by accident of birth or marriage, the workings of patriarchal hierarchy are clear, even within feminized professions such as education. These patriarchal constructions prevail with the assumption that charisma, charm, testosterone, or other essentialist qualities are necessary for those in leadership positions. This perspective works against women. If leaders are not born, but made-in their own likeness-there is no possibility for the transformation, which is needed to change the world. We need to learn, not from past leaders, but from the present struggles for equality and justice.

\section{After-Effects and Future Prospects}

The trip to Highlander demonstrated what can be done and the benefits of maintaining an independent educational center defined by a commitment to equality, freedom, and democracy over a long period of time. It has prompted us to think about how we understand leadership. We have included these insights into our programs, from undergraduate to doctoral 
levels, to inspire and co-create new thinking on authentic leadership. We have, in many ways, brought Highlander back with us into our practice and into our places of work.

Like Horton (2003), we know popular education is not enough "to bring about fundamental social change," but it can "provide practice in analyzing experiences ... give a glimpse of a more humane society" and hopefully "stimulate and enhance and set into motion a yeasty, self-multiplying process" (p. 27) in which participatory and egalitarian practices are shared and developed. Although our efforts in social centers, community education, political groups and campaigns, and in the university have never had the impact that Highlander has had, we regard ourselves simply as one small element of global effort to build a new society in the shell of the old.

However, we would say that popular education is crucial for meeting the challenges of the age. Formal educational institutions dominated by traditional pedagogies are incapable of developing education, which can respond "to the new economic and socio-political dislocations and configurations of our time with the startling realities of human interdependence" (Said, 1994, p. 410). We are in an era pregnant with possibility, but these are also dangerous times of profound crises. Social inequalities, measured either in power or wealth, have become sharper across the globe (Dorling, 2015; Sayer, 2014), and on the horizon is grave ecological degradation. We believe participatory democracy on a global scale, requiring active, informed critical citizens and a whole new conception of leadership, offers the most likely and perhaps the only progressive road toward the future.

\section{Conflict of Interest}

The author(s) declared no potential conflicts of interest with respect to the authorship and/or publication of this article.

\section{Funding}

The author(s) received no financial support for the research, authorship, and/or publication of this article.

\section{References}

Adams, F., \& Horton, M. (1975). Unearthing seeds of fire: The idea of Highlander. Winston-Salem, North Carolina: John Blair.
Arnold, M. (1960). Culture and anarchy. Cambridge, UK: Cambridge University Press.

Brookfield, S. (1995). Becoming a critically reflective educator. San Francisco, CA: Jossey-Bass.

Castoriadis, C. (2010). A society adrift: Interviews and debates. New York, NY: Fordham University Press.

Connolly, L. (2002). The Irish women's movement: From revolution to devolution. London, England: Palgrave.

de Beauvoir, S. (2010). The second sex. London, England: Vintage. (Original work published 1949)

Dorling, D. (2015). Injustice: Why inequality still persists. London, England: Policy Press.

Freire, P. (1972). The pedagogy of the oppressed. London, England: Penguin.

Harré, R. (1993). Social being (2nd ed.). Oxford, UK: Blackwell. hooks, b. (1994). Teaching to transgress: Education as the practice of freedom. London, England: Routledge.

hooks, b. (2000). Feminism is for everyone: Passionate politics. London, England: Pluto Press.

Horton, M. (2003). The Myles Horton reader: Education for social change (D. Jacobs, Ed.). Knoxville: Tennessee University Press.

Horton, M., \& Freire, P. (1990). We make the road by walking: Conversations on education and social change. Philadelphia, PA: Temple University Press.

Hume, D. (2009). A treatise of human nature: Being an attempt to introduce the experimental method reasoning into moral subjects. Auckland, New Zealand: The Floating Press.

Kittay, E. F. (1999). Love's labor: Essays on women, equality and dependency. London, England: Routledge.

Lorde, A. (1994). The master's tools will never dismantle the master's house. In A. Lorde (Ed.), Sister outsider: Essays and speeches (pp. 110-114). Berkeley, CA: Crossing Press.

Lynch, K., Baker, J., Lyons, M., \& Cantillon, S. (2009). Affective equality: Love, care and injustice. Basingstoke, UK: Palgrave Macmillan.

Said, E. W. (1994). Culture and imperialism. London, England: Vintage.

Sayer, A. (1992). Method in social science: A realist approach (2nd ed.). London, England: Routledge.

Sayer, A. (2014). Why we can't afford the rich. Bristol, UK: Policy Press.

Sen, A. (1999). Development as freedom. Oxford, UK: Oxford University Press.

Shor, I. (1987). Critical teaching and everyday life. Chicago, IL: University of Chicago Press.

Vygotsky, L. (1978). Mind in society: The development of higher psychological processes. Cambridge, MA: Harvard University Press. 
Wainwright, H. (2009). Reclaim the state: Experiments in popular democracy. Calcutta, India: Seagull Books.

Wright, E. O. (2010). Envisioning real utopias. London, England: Verso.

\section{Author Biographies}

Brid Connolly has worked in adult and community education for nearly three decades. Her research interests include feminist and critical pedagogy, intersectionality, and group work in adult learning.
Fergal Finnegan is an adult educator and activist from Dublin and is a lecturer in the Department of Adult and Community Education, Maynooth University. His research interests include equality, democracy, social class, critical realism, and more broadly the role of education in relation to state formation, political economy, and social movements. 
Copyright of Adult Learning is the property of Sage Publications Inc. and its content may not be copied or emailed to multiple sites or posted to a listserv without the copyright holder's express written permission. However, users may print, download, or email articles for individual use. 